\title{
Dispositional fear, negative affectivity, and neuroimaging response to visually suppressed emotional faces
}

\author{
Nathalie Vizueta $^{\mathrm{a}, *, 1}$, Christopher J. Patrick ${ }^{\mathrm{b}}$, Yi Jiang ${ }^{\mathrm{c}}$, Kathleen M. Thomas ${ }^{\mathrm{d}}$, Sheng He ${ }^{\mathrm{a}}$ \\ a Department of Psychology, University of Minnesota, 75 E River Road, Minneapolis, MN, USA \\ b Department of Psychology, Florida State University, 1107 W Call Street, Tallahassee, FL, USA \\ c Key Laboratory of Mental Health, Institute of Psychology, Chinese Academy of Sciences, 4A Datun Road, Beijing, P.R. China \\ d Institute of Child Development, University of Minnesota, 51 E River Road, Minneapolis, MN, USA
}

\section{A R T I C L E I N F O}

\section{Article history:}

Received 7 February 2011

Revised 3 July 2011

Accepted 6 July 2011

Available online 14 July 2011

\section{Keywords:}

Amygdala

Binocular rivalry

Invisible faces

Functional MRI

Continuous flash suppression

Individual differences

\begin{abstract}
A B S T R A C T
"Invisible" stimulus paradigms provide a method for investigating basic affective processing in clinical and nonclinical populations. Neuroimaging studies utilizing continuous flash suppression (CFS) have shown increased amygdala response to invisible fearful versus neutral faces. The current study used CFS in conjunction with functional MRI to test for differences in brain reactivity to visible and invisible emotional faces in relation to two distinct trait dimensions relevant to psychopathology: negative affectivity (NA) and fearfulness. Subjects consisted of college students $(\mathrm{N}=31)$ assessed for fear/fearlessness along with dispositional NA. The main brain regions of interest included the fusiform face area (FFA), superior temporal sulcus (STS), and amygdala. Higher NA, but not trait fear, was associated with enhanced response to fearful versus neutral faces in STS and right amygdala (but not FFA), within the invisible condition specifically. The finding that NA rather than fearfulness predicted degree of amygdala reactivity to suppressed faces implicates the input subdivision of the amygdala in the observed effects. Given the central role of NA in anxiety and mood disorders, the current data also support use of the CFS methodology for investigating the neurobiology of these disorders.
\end{abstract}

(c) 2011 Elsevier Inc. All rights reserved.

\section{Introduction}

Individual differences in affective processing and regulation, theorized to entail abnormalities in amygdala reactivity, have been implicated in various forms of psychopathology-in particular, mood and anxiety ("internalizing") disorders (Altshuler et al., 2005; Anand and Shekhar, 2003; McClure et al., 2007; Phan et al., 2006; Rauch et al., 2003; Thomas et al., 2001). However, normal processing of visible emotional stimuli entails recruitment of complex feed-forward and feedback connections involving other brain regions such as the hippocampus, anterior cingulate, and prefrontal cortex (Ghashghaei et al., 2007; Hoistad and Barbas, 2008). Thus, an issue in interpreting reactivity differences in clinical samples tested within standard stimulus-processing tasks is whether affective deficits reflect deviations at the level of the amygdala, or at other points in the distributed processing network. The use of "invisible" processing tasks employing affective stimuli offers a unique research strategy for examining

\footnotetext{
* Corresponding author at: UCLA Mood Disorders Research Program, 300 Medical Plaza, Suite 1544, Los Angeles, CA 90095-7057. Fax: +1 3107949915.

E-mail address: nathalievizueta@ucla.edu (N. Vizueta).

1 Present Address: Department of Psychiatry and Biobehavioral Sciences, David Geffen School of Medicine at UCLA, and Semel Institute for Neuroscience and Human Behavior, Los Angeles, CA, USA.
}

amygdala response (Pasley et al., 2004; Whalen et al., 1998; Williams et al., 2004) with reduced involvement of top-down interactions and feedback within the network (Amting et al., 2010). However, relatively few studies to date have utilized invisible processing tasks to examine amygdala reactivity differences in relation to internalizing disorders (Armony et al., 2005; Dannlowski et al., 2007, 2008; Felmingham et al., 2010; Monk et al., 2008; Rauch et al., 2000; Suslow et al., 2010; Victor et al., 2010) or affiliated personality traits (Etkin et al., 2004).

Researchers have used varying methods to operationalize invisible emotional processing, including very brief stimulus presentations and visual masking. An intriguing alternative is the technique of binocular rivalry (Kim and Blake, 2005), in which differing stimuli are presented separately but simultaneously to the two eyes, resulting in only one stimulus being visible at a given time (Blake and Logothetis, 2002). Compared with visual masking, binocular rivalry offers unique advantages, including neurophysiological evidence showing that the suppressed image does not have significant representation in ventral high-level visual areas (Blake and Logothetis, 2002). Continuous flash suppression (CFS), a variant of binocular rivalry, uses high-contrast dynamic noise presented to one eye to suppress stimuli presented to the other eye (Fang and He, 2005, 2006; Jiang et al., 2009; Tsuchiya and Koch, 2005). A distinct feature of CFS is that the timing of suppressed stimulus presentations (i.e., periods of invisibility of visual images) can be controlled experimentally. 
Prior research utilizing CFS or standard binocular rivalry in unselected participants has demonstrated amygdala reactivity to emotional faces under invisible as well as visible viewing conditions (Jiang and He, 2006; Pasley et al., 2004; Williams et al., 2004). The current study used CFS along with fMRI to examine the brain response to invisible affective stimuli in individuals assessed on two key trait dimensions relevant to internalizing disorders: negative affectivity (NA) and dispositional fear. Our focus on affective trait dimensions coincides with recent calls by mental health experts for increases in neurobiologically-oriented research targeting basic dispositions relevant to psychopathology (Insel et al., 2010; Sanislow et al., 2010). In this regard, NA is a broad construct that encompasses tendencies toward anxiousness, depression, neuroticism, and general distress (Watson, 2005). By contrast, trait fear is defined by measures reflecting experienced levels of fear in relation to specific objects and situations (Kramer et al., 2011; Patrick and Bernat, 2010; Vaidyanathan et al., 2009a).

Neurobiologically, states of fear and of anxiousness or distress that characterize NA can be viewed as reflecting activity in overlapping but dissociable subcircuits of the brain's defensive motivational system (Davis, 2006; Davis and Shi, 1999; Walker et al., 2003). Fear reflects time-limited (phasic) emotional activation in response to specific threat cues (Walker and Davis, 2008), marked physiologically by visceralsomatic arousal (including elevated cardiac and electrodermal activity, muscle tension, and reflex priming) and psychologically by increased alertness to specific signals of threat or imminent danger that helps to facilitate adaptive action (Sullivan, 1949). Anxiousness or distress can also entail physiological arousal, but the arousal lacks a specific external referent and tends to be of lesser intensity and greater duration. Further, anxiety is marked by distinct cognitive-attentional features, including pessimistic thoughts, anticipation of problems, generalized hypervigilance, and a sense of uncontrollability. These features tend to hamper rather than facilitate effective detection, processing, and encoding of environmental stimuli in the service of adaptive response.

Dispositionally, fearfulness and NA can be viewed as related but distinguishable personality traits with differing physiological correlates (Buss and Plomin, 1984; Hicks and Patrick, 2006; Vaidyanathan et al., 2009b) and distinctive relations with particular types of internalizing disorders. Specifically, cue-specific fear characterizes the phobic disorders whereas general anxiousness or NA is more characteristic of the distress disorders (Barlow, 2002; Watson, 2005). Nonetheless, experimental studies have yielded evidence of basic affective processing deviations in relation to both, using different types of task procedures. Individuals high in dispositional fear (relative to those low in fear) show heightened startle reflex potentiation (indicative of amygdala-driven defensive activation; Davis, 1986; Lang et al., 1990) during viewing of threatening scenes (Vaidyanathan et al., 2009a), and individuals diagnosed with phobias show augmented emotional reactivity to fearrelevant stimuli even under presentation conditions that limit visual processing (Globisch et al., 1999; Ohman and Soares, 1994). Individuals high in NA or exhibiting distress disorders such as generalized anxiety or depression show enhanced processing of incidental affective cues in competing-stimulus paradigms (Edwards et al., 2010a,b; Hammar et al., 2009; Jansson and Najstrom, 2009) and heightened amygdala response to mildly aversive or ambiguous stimuli such as angry, fearful, or even neutral facial expressions (Chan et al., 2009; Dickie and Armony, 2008; Etkin et al., 2004; Ewbank et al., 2009; Stein et al., 2007). These findings suggest that high levels of dispositional fear and high levels of dispositional NA are both associated with affective processing deviations, but perhaps of differing types. In particular, findings from studies investigating fear and phobic disorders suggest deviations in processing of specific aversive cues at a basic subcortical level, whereas findings from studies investigating NA and distress disorders suggest more diffuse affective processing deviations, potentially reflecting impairments at higher brain levels.

The current study was conducted to clarify affective reactivity differences associated with these key individual difference constructs in order to advance understanding of emotional processing deviations in internalizing forms of psychopathology (cf. Sanislow et al., 2010). Specifically, we examined differences in brain reactivity to visible and invisible emotional faces in relation to trait dimensions of fearfulness and NA, each operationalized as a composite of multiple established measures. This composite-measure approach enabled us to tie effects to broad dimensions common to differing assessment instruments and thereby enhance generalizability of observed results. Happy and surprised faces were included as stimuli along with fearful faces to provide for evaluation of the specificity of effects observed for fearful faces. Guided by prior work (Jiang and He, 2006), we focused on three core regions of the brain's face processing network (Haxby et al., 2000): fusiform face area (FFA), superior temporal sulcus (STS), and the amygdala. On the basis of existing published data (Chan et al., 2009; Dickie and Armony, 2008; Etkin et al., 2004; Ewbank et al., 2009; Stein et al., 2007; Vaidyanathan et al., 2009a), we predicted that dispositional fear and NA would both be associated with enhanced reactivity to affective face stimuli, but in differing ways. First, given evidence that fear and fear-related disorders entail heightened sensitivity to explicit aversive cues at the basic subcortical (i.e., amygdala) level (Globisch et al., 1999; Vaidyanathan et al., 2009a), we predicted that high levels of dispositional fear would be associated with enhanced reactivity to fear faces under invisible as well as visible processing conditions, whereas high NA would be associated with enhanced reactivity to fear faces primarily under visible processing conditions. Second, based on conceptual and empirical considerations, we predicted that dispositional fear would predict enhanced brain reactivity to fear faces specifically, whereas dispositional NA would predict differential reactivity to other types of emotional stimuli as well.

\section{Material and methods}

\section{Participants}

Participants consisted of undergraduates who completed screening questionnaires on-line for course credit. Because less research exists on dispositional fear as a predictor of fMRI brain response to affective stimuli than on NA-related constructs (Bishop et al., 2007; Chan et al., 2009; Dickie and Armony, 2008; Etkin et al., 2004; Ewbank et al., 2009; Haas et al., 2007; Stein et al., 2007), we sought to maximize power to detect associations for dispositional fear by including in the test sample subsets of participants scoring either very high (top $20 \%$ of screening disposition; $n=12$ ) or very low (bottom $20 \% ; n=12$ ) on an omnibus inventory of trait fear (see Trait fear section below); participants with intermediate levels of trait fear (middle $20-80 \%$ of score distribution; $n=12$ ) were also included to permit continuous score (correlational) analyses. All participants provided written informed consent prior to testing. Three had to be replaced after testing due to excessive head motion during scanning. Five of the final 36 test participants were excluded due to problems that became evident at the data processing stage (i.e., targeted a priori ROIs not identifiable from a functional localizer scan, $n=3$; above-chance performance on a post-test evaluation of visual-suppression effectiveness, $n=2$ ), leaving 31 for analyses ( 17 female, $M_{\text {age }}=19.6 \pm 1.3$ years).

\section{Prescreening}

Individuals taking psychotropic medications or reporting abnormal neurological history, visual impairments, or a history of severe head trauma were excluded from testing. Also excluded were individuals meeting diagnostic criteria at the time of testing for a mood disorder, posttraumatic stress disorder, generalized anxiety disorder, social phobia, or psychosis as assessed by the SCID-I (First et al., 2007), or borderline personality disorder as assessed by the SCID-II (First et al., 1997). 


\section{Self-report trait measures}

\section{Trait fear}

Participants were assessed for levels of dispositional fear using an omnibus measure (Kramer et al., 2011; Patrick and Bernat, 2010) consisting of 55 items drawn from various established self-report inventories of fear and fearlessness, including the Fear Survey Schedule-III (Arrindell et al., 1984), the Fearfulness subscale of the EAS Temperament Survey (Buss and Plomin, 1984), the Harm Avoidance subscale of the Temperament and Personality Questionnaire (Cloninger, 1987), subscales comprising Factor 1 of the Psychopathic Personality Inventory (Lilienfeld and Andrews, 1996), and the Thrill/Adventure Seeking subscale of the Sensation Seeking Scale (Zuckerman, 1979) (see Supplement 1 for a list of the item numbers). Scores on the 55-item Trait fear measure used in the current study correlate very highly $(r>.9)$ with scores on the general fear/fearlessness factor that these various inventories assess in common $^{2}$ (Kramer et al., 2011; Patrick and Bernat, 2010; Vaidyanathan et al., 2009a). Descriptive statistics for this measure in the current sample were: $M=1.37, S D=0.56$, range $=0.47$ to 2.33 .

\section{Negative affectivity}

Negative affectivity (NA) is conceptualized as a broad dispositional factor reflecting variance in common among differing self-report measures related to internalizing ( $\operatorname{mood}$ and anxiety) disorders (Watson, 2005; Watson and Tellegen, 1985). To establish representation of differing scale indicators relevant to NA and to maximize the generalizability of findings, we operationalized NA as a composite of established measures of anxiousness, depression, and dispositional negative emotionality. Specifically, indicators of NA in the current study included the Trait Anxiety subscale of the State-Trait Anxiety Inventory (STAI-trait; Speilberger, 1983), the Beck Depression Inventory-II (BDI-II; Beck et al., 1996), and the broad trait of negative emotionality (NEM) from the brief form (Patrick et al., 2002) of the Multidimensional Personality Questionnaire (MPQ; Tellegen, 2003).

Descriptive statistics for these measures in the current sample were: STAI-trait, $M=32.48, S D=6.11$, range $=25$ to 49 ; BDI-II, $M=3.97$, $S D=4.00$, range $=0$ to $19 ; \mathrm{MPQ}-\mathrm{NEM}, M=45.77, S D=9.93$, range $=29$ to 71. As expected from prior published work (Clark and Watson, 1991; Tellegen, 1985; Watson, 2005; Watson and Tellegen, 1985), scores on these measures were substantially intercorrelated (.61-.73) within the current sample, and a principal components analysis (PCA) of scores on the three measures revealed a single dominant component (eigenval$\mathrm{ue}=2.37$ ) accounting for most $(79 \%)$ of their shared variance. The loadings of the three individual measures on this component, labeled negative affectivity (NA), were: STAI Trait Anxiety, .80; BDI-II, .77; and MPQ-NEM, .92. Hence, the three measures were aggregated into a composite index of NA corresponding to scores on the first principal component from the PCA. Consistent with the idea that dispositional NA and trait fear represent related but distinguishable constructs, scores on this NA component correlated significantly, but only moderately $(r=.45, p<.01)$ with scores on the aforementioned Trait Fear measure.

\section{Experimental stimuli and task}

Face stimuli were neutral, happy, fearful, and surprised expressions from the NimStim set (Tottenham et al., 2009). Scrambled stimuli consisted of faces segmented into $18 \times 24$ square grids and randomly rearranged. Participants viewed stimuli through red-blue anaglyph eyeglasses. A central fixation point $\left(0.3^{\circ} \times 0.3^{\circ}\right)$ surrounded

\footnotetext{
${ }^{2}$ The trait fear measure and a description of the procedures used to develop it can be obtained from the authors upon request.
}

by a rectangular frame $\left(5.7^{\circ} \times 7.5^{\circ}\right)$ was continuously presented to both eyes to facilitate stable convergence of the two eyes' images. Participants were instructed to press a button when the fixation point (a circle with $10 \times 10$ pixels) changed in size (e.g., fixation changed either to a larger circle $(16 \times 16)$ or a smaller one $(4 \times 4))$. In the invisible condition (Fig. 1A), 2-s dynamic noise patterns $\left(4.2^{\circ} \times 5.7^{\circ}\right)$ consisting of flashing colored squares (Jiang and He, 2006) were presented to the dominant eye through the red filter, simultaneous with scrambled or intact faces (also $4.2^{\circ} \times 5.7^{\circ}$ ) to the other eye through the blue filter for the same duration (2-s). For the invisible stimuli, the red-color channel of the face pictures was entirely replaced with the dynamic noise patterns so that subjects could not perceive the facial stimuli when wearing the anaglyph glasses. The intact or scrambled faces were not visible to the observers because of interocular suppression from the high contrast and dynamic noise presented to the other eye. Stimulus trials were separated by 2-s intertrial intervals in which only the binocular fixation and frame were presented. Following each invisible scan, participants were asked whether they saw any faces or parts of faces other than the noise patterns. In the visible condition (Fig. 1B), the same face stimulus was presented to both eyes. Scans in each condition (visible, invisible) included faces of all five types (neutral, happy, fearful, surprised, scrambled) presented in counterbalanced (M-sequence) order (Buracas and Boynton, 2002).

\section{fMRI data acquisition}

Images were acquired on a 3T Siemens Magnetom Trio scanner using an 8-channel phased-array coil. Anatomical and functional images were acquired, respectively, using a high-resolution 3D MPRAGE sequence (TE/TR: $3.02 \mathrm{~ms} / 2600 \mathrm{~ms}$; FOV: $256 \mathrm{~mm}$; $1 \mathrm{~mm}$ slice thickness, 0 gap, flip angle: $8^{\circ}, 176$ sagittal slices; $256 \times 256$ matrix) and an echo-planar imaging sequence (TE/TR: $25 \mathrm{~ms} / 2000 \mathrm{~ms}$; FOV: $192 \mathrm{~mm} ; 3 \mathrm{~mm}$ slice thickness, 0 gap; flip angle: $80^{\circ}$; 36 slices; $64 \times 64$ matrix; slice orientation tilted $30^{\circ}$ from the axial to coronal plane). Functional scans for the visible and invisible conditions (four and eight, respectively) were run separately in randomized order. Each scan commenced with a 4-s rest period, followed by two successive blocks of 25 event-related trials; each 25 -trial block was followed by a 16 -s rest period.

\section{Regions of interest (ROIs)}

To functionally define ROIs for face-specific areas, a separate localizer scan was conducted following the CFS procedure in which participants passively viewed four alternating 20 -s blocks of stimuli (neutral faces, fearful faces, non-face objects, scrambled faces/objects).

As detailed in methods already published (Jiang and He, 2006), faceselective ROIs were defined as areas that responded more strongly to intact faces relative to nonface objects, using a boxcar response model smoothed with a hemodynamic response function to identify high signal $\left(\mathrm{p}<10^{-4}\right)$ voxels, and applying Bonferroni correction for multiple comparisons $(p<.05)$. Following prior work (Jiang and He, 2006), analyses focused on the right FFA and STS. Significant face-specific activation in right FFA (Fig. 2A) was seen in 29 of the 31 participants, with mean Talairach coordinates of: $x y z=38 \pm 1,-47 \pm 2,-18 \pm 1$. Significant face-specific activation in right STS (Fig. 2B) was seen in 26 of 31 participants, with mean Talairach coordinates of: $x y z=47 \pm 1$, $-50 \pm 2,9 \pm 1$.

Bilateral amygdala regions (Fig. 2C) for each participant were identified from the localizer scan by contrasting neutral and fearful faces with scrambled faces (Fitzgerald et al., 2006; Jiang and He, 2006; Johnstone et al., 2005). Significant activation in right amygdala (mean $x y z=19 \pm 1,-4 \pm 1,-12 \pm 2$ ) was seen in 20 of 31 participants, and corresponding left amygdala activation (mean $x y z=-17 \pm 1$, $-6 \pm 1,-12 \pm 1$ ) was evident in 16 . 


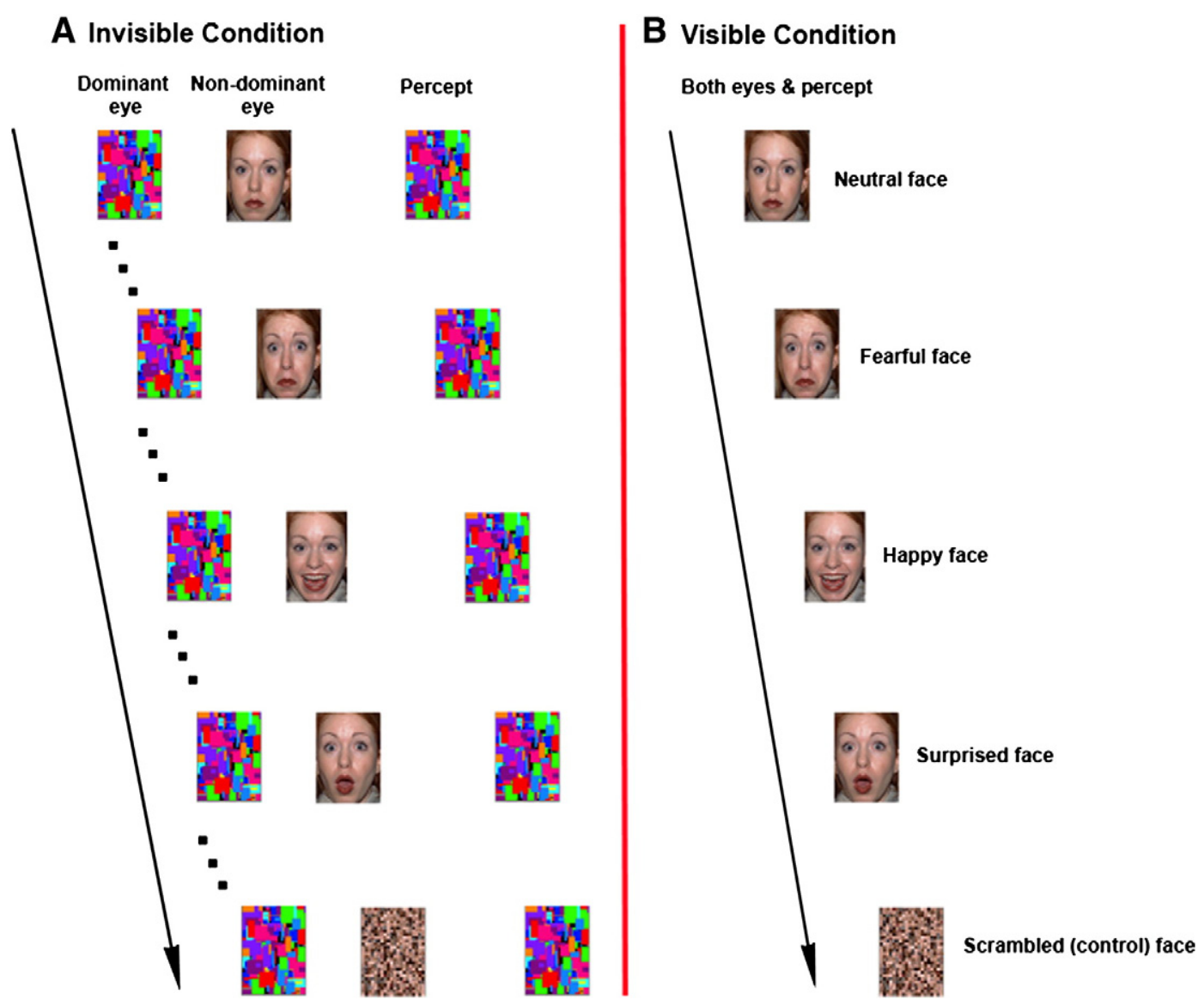

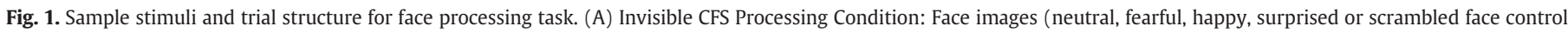

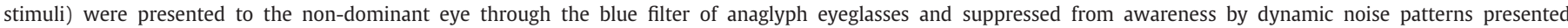

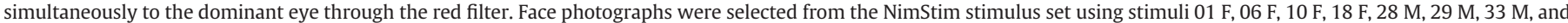

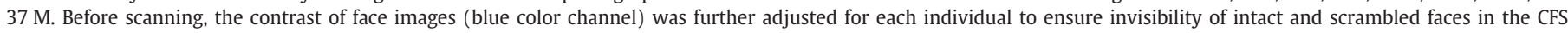

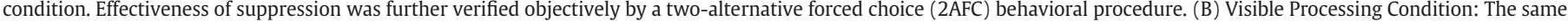
intact face or scrambled face stimulus was presented to both eyes.

A Fusiform Face Area

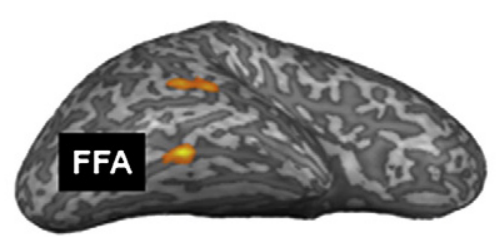

B Superior Temporal Sulcus

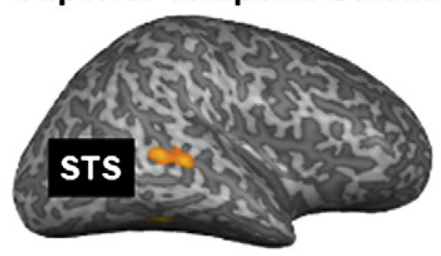

\section{Amygdala}

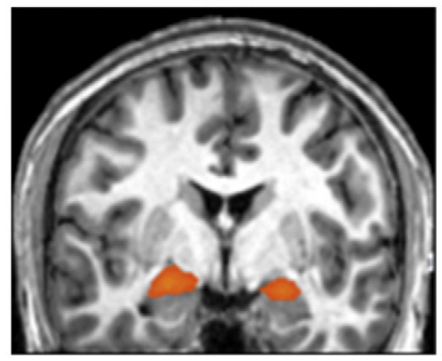

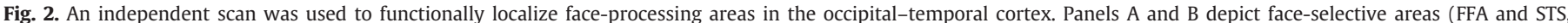

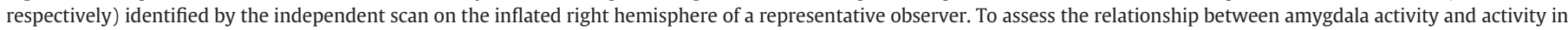

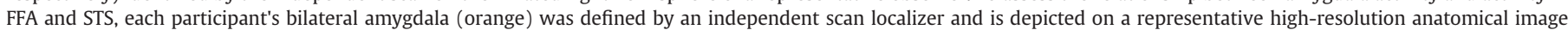
(depicted in panel C). 


\section{Post-task assessments}

\section{Objective measure of suppression effectiveness}

Following the fMRI experimental paradigm, participants completed 100 trials of a two-alternative forced choice (2AFC) task to assess for participants' awareness of the suppressed stimuli. Each trial consisted of two successive temporal intervals, each $2 \mathrm{~s}$ in duration, separated by a 500-ms blank gap. Intact faces were presented randomly in the first or the second interval and a scrambled face was presented in the other interval. Participants pressed one of two buttons to indicate whether the face occurred in the first or second interval. Two of the 36 participants performed at above chance level on the 2AFC; these participants were excluded from the analyses.

\section{Affective stimulus ratings}

Following the scanning procedures, participants rated the perceived impact of each intact face stimulus on dimensions of valence (pleasure) and arousal using the Self-Assessment Manikin pictorial rating system (SAM; Lang, 1980). The valence scale ranged from maximally unpleasant (1) to maximally pleasant (9), and the arousal scale ranged from calm (1) to highly excited (9). As a manipulation check, mean SAM ratings for face stimuli in this experiment were examined: Valence: fearful faces $=3.61 \pm 0.91$, neutral faces $=4.18 \pm$ 0.76 , happy faces $=6.80 \pm 1.37$, surprised faces $=4.74 \pm 1.11$; Arousal: fearful faces $=4.94 \pm 1.69$, neutral faces $=3.47 \pm 1.21$, happy faces $=$ $5.15 \pm 1.82$, surprised faces $=5.46 \pm 1.78$. Participants also identified the emotion displayed by each face stimulus from among the following response options (1-“Anger”, 2-“Disgust”, 3-“Fear”, 4-“Neutral”, 5-“Happy”, 6-“Sad” or 7-“Surprised”).

\section{fMRI analysis}

Functional MR image analysis was performed using BrainVoyager QX v1.9 (Brain Innovation, Maastricht, Netherlands). To reduce T1 saturation effects, the first two functional volumes in each scan were discarded. Preprocessing included normalization of global signal intensity of each slice across each volume, sinc interpolation for slice scan time correction, 3D motion correction (with the first volume as reference, a six-parameter, rigid-body, transformation algorithm, and a translation/rotation mean threshold of $1 \mathrm{~mm} /$ degrees to eliminate participants due to excessive movement) and high-pass ( $3 \mathrm{~Hz}$ ) temporal filtering to remove slow drift. Functional images were spatially realigned to the first T1-saturated volume using a trilinear sinc interpolation algorithm. Spatial data smoothing was performed using a 3D Gaussian kernel (FWHM $=6 \mathrm{~mm}$ ), and coregistered with anatomical images and transformed into Talairach space (Talairach and Tournoux, 1988).

After ROIs were defined, the signal intensity time course data of activation from each ROI was extracted and imported into MATLAB for further analyses. For each scan, the signal intensity across the 10 trials in each condition at each of 11 time points (from $-2 \mathrm{~s}$ to $18 \mathrm{~s}$ ) was averaged. These average signal intensity values were converted to percent signal change by subtracting the corresponding value for the scrambled face condition and then dividing by that value. Percent change scores for each condition were then averaged across scans and participants. Within a $2 \mathrm{~s}$ to $10 \mathrm{~s}$ window, the peak of the observed event-related averages served as the measured BOLD response for each condition and each individual. The difference in BOLD signal for each of the emotional categories (fearful, happy, surprised) relative to neutral was computed for each participant and utilized in analyses. For correlational analyses, an outlier correction was applied in which outlying score values were reigned-in to a value of 2.5 SDs from the sample mean.

Across the sample as a whole, for the visible and invisible processing conditions separately and for each ROI, one sample t-tests were used to evaluate activations for each face stimulus type (fear, surprise, happy, neutral) against the scrambled face baseline condition. For each ROI (FFA, STS, right and left amygdala) in both visible and invisible conditions, all face types (fear, surprise, happy, neutral) showed increased activation relative to scrambled faces $(p s<.001)$. Therefore, for the sample as a whole, we report the activations specifically for affective faces relative to neutral faces. To evaluate activations for affective faces compared to neutral in visible versus invisible processing conditions across the sample as a whole, separate Affect/Neutral x Visible/Invisible repeated measures ANOVAs were run for each affective face type and each ROI. Correlational analyses testing for concordance across ROIs in the degree of activation for each affective face type relative to neutral were also performed.

To evaluate individual difference effects, two types of analyses were performed: (1) correlations between individual difference variables (NA, trait fear) and the differential BOLD activation for affective versus neutral faces, and (2) ANOVAs testing for differences in BOLD responses to affective versus neutral faces across trait fear groups.

\section{Results}

Findings reported in this section are grouped in two subsections. The first presents results of two-way repeated measures ANOVAs examining effects of within-subject manipulations in the sample as a whole. The focus here is on overall effects for fearful faces (and secondarily, affective face of other types) in relation to neutral faces for target regions of interest (FFA, STS, amygdala). The second subsection focuses on analyses examining brain reactivity to fearful and other affective faces, under visible and invisible processing conditions, as a function of individual differences in dispositional fear and negative affectivity.

\section{Overall sample: fMRI responses to emotional versus neutral faces}

\section{Fearful versus neutral faces}

Two-way (Affective/Neutral $\times$ Visible/Invisible) ANOVAs were conducted for each affective face type and each ROI (Table 1). For fearful versus neutral faces, a significant main effect of awareness condition was found for FFA, reflecting greater activity in the visible $(M=.37$, $S D=.15)$ than the invisible condition $(M=.09, S D=.07)$, along with a main effect of face type, reflecting greater activity for fearful $(M=.24$, $S D=.11)$ than for neutral faces $(M=.22, S D=.11)$. Although the Face Type $\mathrm{x}$ Awareness Condition interaction did not achieve significance $\left(F_{1,28}=2.21, p=.149\right)$, mirroring earlier findings (Jiang and He, 2006), comparisons of responses to fearful and neutral faces for the two awareness conditions separately revealed significantly enhanced FFA activation for fearful faces in the visible condition only (Fig. 3), $t(28)=$ $2.46, p=.02$ (invisible condition $t(28)=.19, p=.849$ ).

For STS, main effects were again found for both awareness condition and face type. Although the magnitude of the fear-neutral difference appeared larger in the visible than the invisible condition (Fig. 3), there was no hint of an Awareness Condition $\times$ Face Type interaction in this case $\left(F_{1,25}=.49, p=.489\right)$-indicating comparable differentiation between these face types in the STS region across the two awareness conditions, relative to levels of overall reactivity within each.

For both the right and left amygdala, a significant main effect of awareness condition was found (right amygdala: $F_{1,19}=6.06, p=.024$; left amygdala: $F_{1,15}=25.41, p<.001$ ), but in neither case was the main effect of face type significant, nor was the two-way interaction ${ }^{3}$ (see Table 1 top section).

\footnotetext{
3 The lack of amygdala differentiation for fearful versus neutral faces in the visible condition for participants as a whole contrasts with demonstrations of this effect in several prior studies (Jiang and He, 2006; Pasley et al., 2004; Whalen et al., 1998; Williams et al., 2004). A possible explanation for the discrepancy is that in contrast with prior studies that have utilized unselected participants, the current study examined individuals preselected to be either high or low in trait fear, with some representation also of intermediate-fear individuals. To provide for a more direct comparison with prior fMRI/face-processing work, we examined amygdala reactivity in the subgroup of current participants most comparable to unselected participants-those selected to be intermediate (middle 20\%$80 \%$ ) in trait fear. Consistent with prior findings, this more representative participant subgroup showed enhanced activation for visible fearful versus neutral faces in both the left and right amygdala, $t(4 / 5)=3.10$ and 2.25 , respectively, $p s=.036$ and .074 .
} 
Table 1

Results from repeated measures analyses of variance examining responses to affective faces in comparison to neutral faces across visible and invisible conditions for each ROI.

\begin{tabular}{|c|c|c|c|c|c|}
\hline & ROI & Effect & df & $\mathrm{F}$ & $\mathrm{p}$ \\
\hline \multirow[t]{12}{*}{ Fear versus neutral } & \multirow[t]{3}{*}{ Fusiform face area } & Face type & 1,28 & 5.68 & .024 \\
\hline & & Awareness condition & 1,28 & 95.66 & $<.001$ \\
\hline & & Face type $\times$ awareness & 1,28 & 2.21 & .149 \\
\hline & \multirow[t]{3}{*}{ Superior temporal sulcus } & Face type & 1,25 & 5.42 & .028 \\
\hline & & Awareness condition & 1,25 & 12.10 & .002 \\
\hline & & Face type $\times$ awareness & 1,25 & .49 & .489 \\
\hline & \multirow[t]{3}{*}{ Right amygdala } & Face type & 1,19 & 1.73 & .205 \\
\hline & & Awareness condition & 1,19 & 6.06 & .024 \\
\hline & & Face type $\times$ awareness & 1,19 & .02 & .896 \\
\hline & \multirow[t]{3}{*}{ Left amygdala } & Face type & 1,15 & .04 & .842 \\
\hline & & Awareness condition & 1,15 & 25.41 & $<.001$ \\
\hline & & Face type $\times$ awareness & 1,15 & .00 & .967 \\
\hline \multirow[t]{12}{*}{ Happy versus neutral } & \multirow[t]{3}{*}{ Fusiform face area } & Face type & 1,28 & .76 & .392 \\
\hline & & Awareness condition & 1,28 & 89.20 & $<.001$ \\
\hline & & Face type $\times$ awareness & 1,28 & .20 & .656 \\
\hline & \multirow[t]{3}{*}{ Superior temporal sulcus } & Face type & 1,25 & .27 & 610 \\
\hline & & Awareness condition & 1,25 & 10.81 & .003 \\
\hline & & Face type $\times$ awareness & 1,25 & .23 & .636 \\
\hline & \multirow[t]{3}{*}{ Right amygdala } & Face type & 1,19 & .65 & .429 \\
\hline & & Awareness condition & 1,19 & 5.92 & .025 \\
\hline & & Face type $\times$ awareness & 1,19 & .30 & .593 \\
\hline & \multirow[t]{3}{*}{ Left amygdala } & Face type & 1,15 & .09 & .767 \\
\hline & & Awareness condition & 1,15 & 15.90 & .001 \\
\hline & & Face type $\times$ awareness & 1,15 & 1.24 & .284 \\
\hline \multirow[t]{12}{*}{ Surprise versus neutral } & \multirow[t]{3}{*}{ Fusiform face area } & Face type & 1,28 & .79 & .380 \\
\hline & & Awareness condition & 1,28 & 110.58 & $<.001$ \\
\hline & & Face Type $\times$ awareness & 1,28 & .84 & .368 \\
\hline & \multirow[t]{3}{*}{ Superior temporal sulcus } & Face type & 1,25 & 1.05 & .316 \\
\hline & & Awareness condition & 1,25 & 7.98 & .009 \\
\hline & & Face type $\times$ awareness & 1,25 & .08 & .781 \\
\hline & \multirow[t]{3}{*}{ Right amygdala } & Face type & 1,19 & 2.22 & .152 \\
\hline & & Awareness condition & 1,19 & 4.69 & .043 \\
\hline & & Face type $\times$ awareness & 1,19 & .11 & .741 \\
\hline & \multirow[t]{3}{*}{ Left amygdala } & Face type & 1,15 & .39 & .540 \\
\hline & & Awareness condition & 1,15 & 33.84 & $<.001$ \\
\hline & & Face Type $\times$ awareness & 1,15 & .03 & .872 \\
\hline
\end{tabular}

Correspondence across regions-of-interests in response to fearful faces

As a supplement to these analyses, we computed correlations to evaluate correspondence across ROIs in response to fearful versus neutral faces. In the visible condition, a significant positive relationship was evident between fear/neutral differentiation in the FFA and corresponding differentiation in the STS, $r=.52, p<.01$ (invisible condition $r=.00$ ). On the other hand, in the invisible condition, a significant positive correlation was evident between fear/neutral differentiation in the right amygdala and differentiation in the STS, $r=.58, p<.05$. A positive directional association was also evident between fear/neutral differentiation in the left amygdala and differentiation in the STS, but this relationship did not achieve significance, $r=.25, n s$. Consistent with prior work (Jiang and He, 2006), these results suggest that the mechanism for STS activation was different in the invisible condition as compared to the visible condition.

\section{Other affective faces}

For both happy and surprised faces, a significant main effect of awareness condition was found for FFA, reflecting greater activity in the visible versus invisible condition (happy: $M s=.36$ and .09 ; surprise: $M s=.36$ and .09 ). However, the main effect of face type (affective versus neutral) and the two-way (Awareness Condition $\times$ Face Type) interaction were non-significant in each case, $\left(F s_{1,28}=.20\right.$ and .84 for happy and surprised faces, respectively, $p s=.656$ and .368). For STS, a main effect of awareness condition was again evident for both happy and surprised faces, but in neither case was the main effect of face type significant, nor was the two-way interaction $\left(F s_{1,25}=.23\right.$ and .08 for happy and surprised faces, respectively, $p s=.636$ and 781). Significant main effects of awareness condition were also evident in each case for both the right and left amygdala regions, but main effects of face type and two-way interaction effects were again nonsignificant (see Table 1 ).

\section{Individual difference effects}

Trait fear

Contrary to prediction, no significant association was found between trait fear scores and any affect-neutral BOLD signal differences for any ROI in either the visible or the invisible condition ( $r s=.02-.31$ ). Since the participant sample included specific representation of high (top $20 \%$ of scorers) and low trait fear individuals (bottom 20\%), we also undertook extreme group analyses to supplement the primary correlational analyses. The $n s$ for these extreme subgroups within the final analysis sample $(N=31)$ were 11 and 9, respectively. Consistent with the correlational results, Fear Group $\times$ Awareness Condition (visible, invisible) ANOVAs evaluating differences between these extreme groups in affective differentiation for designated ROIs yielded no significant Group main effects or interactions (all ps>.08).

\section{Negative affectivity}

Table 2 depicts corresponding correlations for the dispositional NA measure; in this Table, $r$ s are evaluated against a corrected significance threshold of $.05 / 4=.0125$ (in consideration of the multiple ROIs examined) as well as against an uncorrected alpha level of .05 (in consideration of the modest study $N$ and our a priori hypotheses). The finding that emerged most robustly (exceeding the more stringent significance threshold) was a positive correlation between NA component scores and fear-neutral BOLD signal differences in the right amygdala within the invisible condition, $r(20)=.554, \mathrm{p}=.011$. 


\section{A Visible Condition}

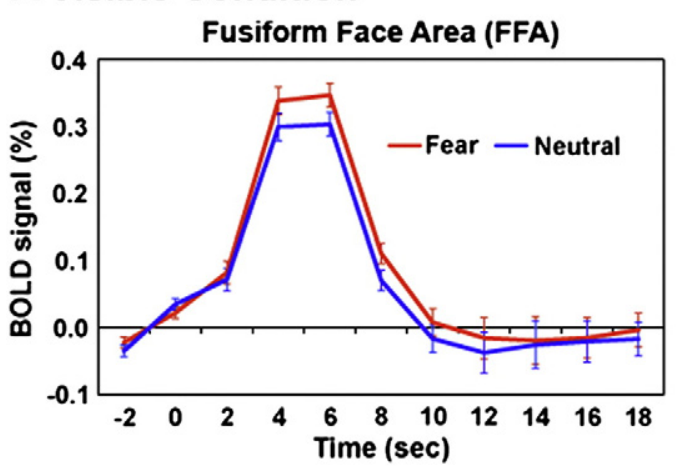

\section{B Invisible Condition}

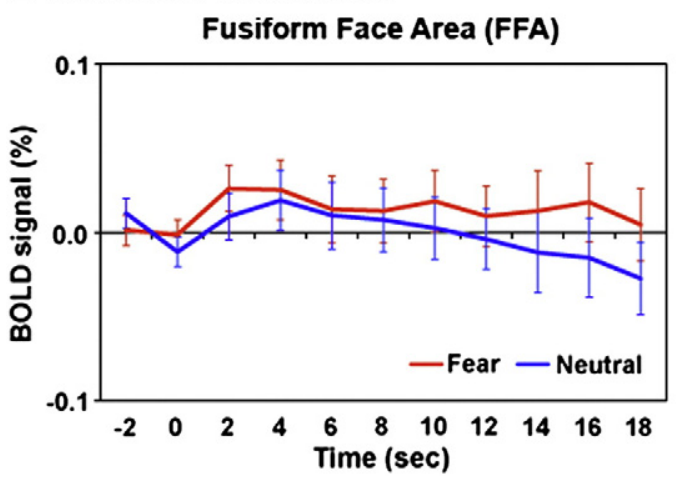

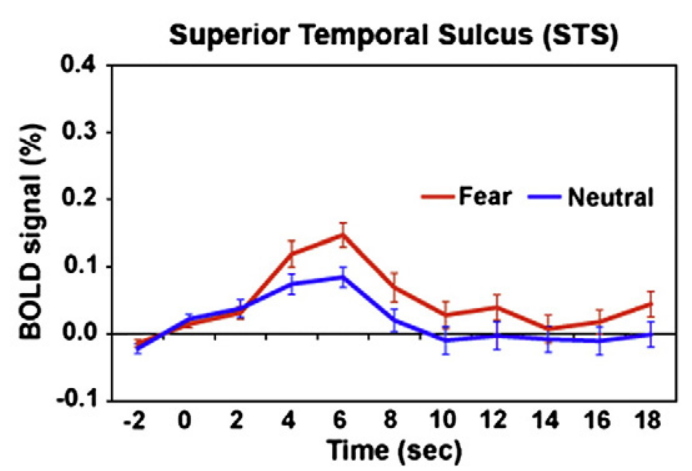

Superior Temporal Sulcus (STS)

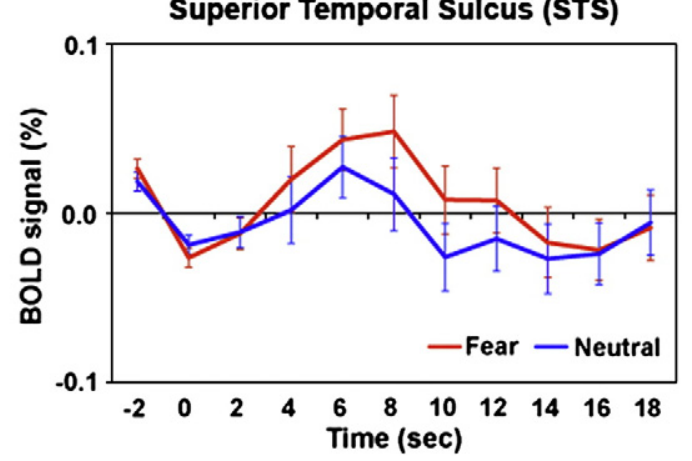

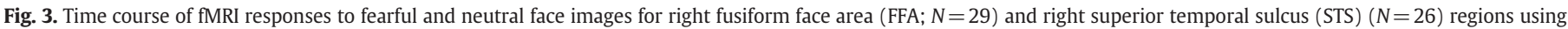

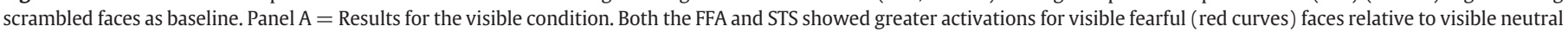

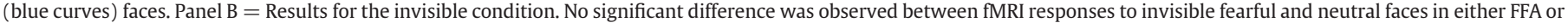
STS regions. Error bars denote standard error of the difference between fMRI response to fearful and neutral face stimuli within the specified time point.

In addition, a corresponding positive association between NA scores and fear-neutral differentiation for the invisible condition, exceeding the more liberal alpha threshold, was evident for the STS, $r(26)=.437$, $\mathrm{p}=.026$. Fig. 4 plots, for these regions, BOLD responses to invisible fear and neutral faces for participants high versus low in NA. From the Figure, it can be seen that although participants as a whole did not show significant right amygdala differentiation for fearful versus neutral faces in the invisible condition, robust differentiation was evident for one specific subgroup of participants-those identified as high in dispositional NA. A correlation in the positive direction (paralleling those for the right amygdala and STS) was evident for the left amygdala, but this association did not achieve significance at either alpha level. No

Table 2

Correlations between negative affectivity component scores and affective differentiation for overall sample.

\begin{tabular}{llll}
\hline Regions-of-interest & $\begin{array}{l}\mathrm{r} \text { with } \\
\text { (fear-neutral) } \\
\text { difference }\end{array}$ & $\begin{array}{l}\text { r with } \\
\text { (happy-neutral) } \\
\text { difference }\end{array}$ & $\begin{array}{l}\text { r with } \\
\text { (surprise-neutral) } \\
\text { difference }\end{array}$ \\
\hline Visible condition & & & .263 \\
1. Fusiform face area & .249 & .317 & .216 \\
2. Superior temporal sulcus & .207 & .234 & .283 \\
3. Right amygdala & .320 & .281 & .477 \\
4. Left amygdala & .171 & .202 & \\
& & & -.269 \\
Invisible condition & & & .226 \\
1. Fusiform face area & -.116 & -.183 & -.042 \\
2. Superior temporal sulcus & $.437^{+}$ & .242 & .282 \\
3. Right amygdala & $.554^{*}$ & $.473^{+}$ & .268 \\
4. Left amygdala & .181 & &
\end{tabular}

\footnotetext{
* Significant at corrected $p<.0125$.
}

+ Significant at uncorrected $p<.05$. corresponding association was observed in the invisible condition for the FFA region.

Since NA and trait fear scores in the current sample were moderately correlated $(r=.45)$, we ran regression models incorporating both trait variables concurrently as predictors of invisible fearinvisible neutral differentiation in the STS and right amygdala regions to confirm that the predictive contribution of NA remained significant after controlling for trait fear. In the model for each region, the predictive relationship for NA remained significant after controlling for trait fear $(\beta s=.552$ and .672 for STS and right amygdala, respectively, $p s=.011$ and .004 ), whereas the association for trait fear was not significant.

Notably, all individual measures of NA (STAI-trait, BDI-II, MPQ$\mathrm{NEM})$ showed positive correlations $(r s=.40-.58)$ significant at one threshold or the other $(.05, .0125)$ with degree of fear-neutral differentiation for both STS and right amygdala (but not FFA) in the invisible condition specifically. Table 3 summarizes the results of hierarchical regression analyses conducted to evaluate whether observed relations of individual NA measures with degree of fearneutral differentiation in STS and right amygdala regions were attributable to the broad NA component reflecting the overlap among these measures. Fear-neutral differentiation for STS and right amygdala BOLD response were entered as dependent variables in these regression analyses. Each individual psychometric measure was entered separately in step 2 to evaluate its prediction after first accounting for variance in NA component scores (step 1). Results indicated that there was no predictive contribution for any of the individual psychometric measures above and beyond the variance associated with the NA component measure.

One other correlation for the NA component measure emerged as significant at the more liberal (.05) threshold, consisting of a positive 

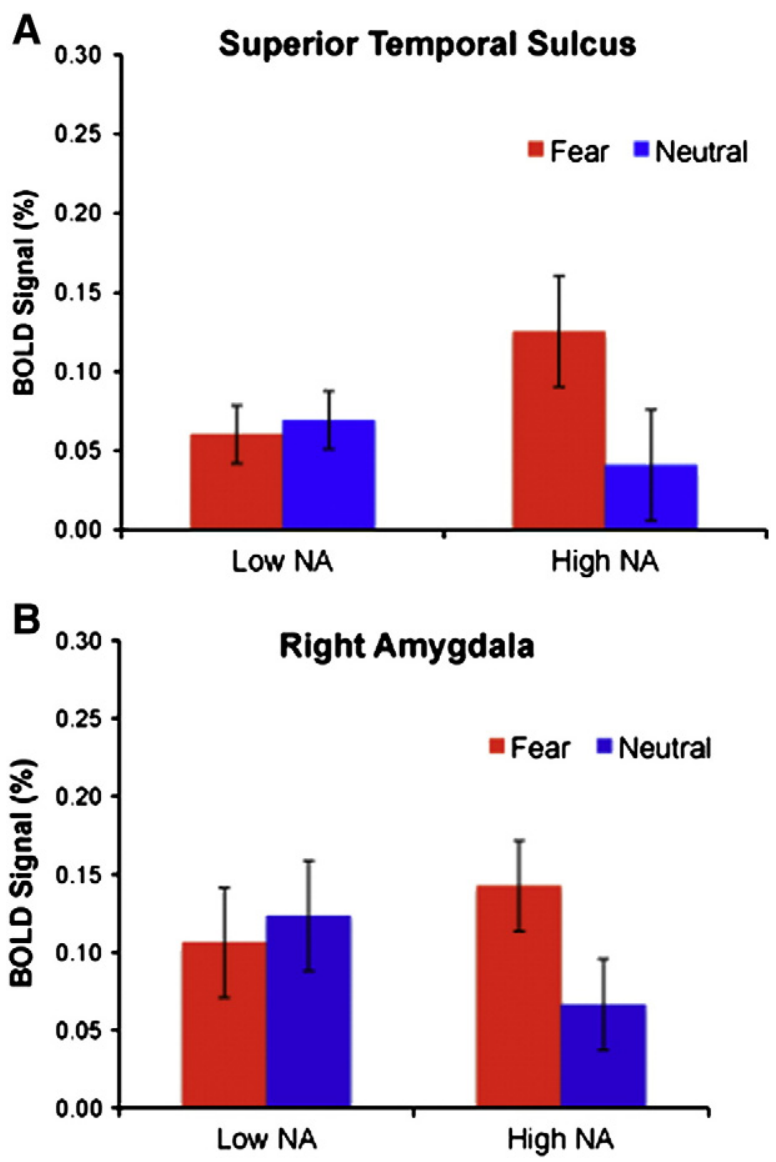

Fig. 4. fMRI response to invisible fearful versus invisible neutral faces in STS and right amygdala in individuals low versus high in negative affectivity (NA). The superior temporal sulcus (A) and right amygdala (B) responded significantly more to invisible fearful faces in high negative affect $(N A)$ individuals $(t(9)=2.39, p=.041$ and $t(7)=2.40, p=.047$, respectively). Conversely, no significant differences were evident in ether STS or amygdala activation between invisible fearful and neutral faces in the low NA group $(\mathrm{t}(8)=-0.51$, $\mathrm{p}=.627$ and $\mathrm{t}(6)=-0.49, \mathrm{p}=.643$, respectively). NA groups are based on a split of NA composite scores whereby high NA= top third of scores in the sample and low NA= bottom third of scores in the sample. Notably, the effect for NA accounted for observed covariation between STS and right amygdala differentiation in the invisible condition for the sample as a whole. Error bars reflect standard error of the difference between fMRI response to invisible fearful and neutral face stimuli.

relationship, in the invisible condition specifically, between NA scores and happy-neutral BOLD signal differentiation in the right amygdala region. To evaluate whether this effect overlapped with the above-

Table 3

Hierarchical regression analyses demonstrating that negative affectivity component scores account for relations between individual psychometric measures and fearneutral differentiation in the invisible condition in the superior temporal sulcus (STS) and right amygdala regions.

\begin{tabular}{|c|c|c|c|c|c|c|c|c|c|c|}
\hline \multirow[b]{2}{*}{ Measure } & \multicolumn{5}{|c|}{$\begin{array}{l}\text { STS BOLD (\%) } \\
\text { fear-neutral difference }\end{array}$} & \multicolumn{5}{|c|}{$\begin{array}{l}\text { Right amygdala BOLD (\%) } \\
\text { fear-neutral difference }\end{array}$} \\
\hline & $r$ & $\mathrm{p}$ & $\begin{array}{l}\text { R square } \\
\text { change }\end{array}$ & $\mathrm{F}$ & $\mathrm{p}$ & $r$ & $\mathrm{p}$ & $\begin{array}{l}\text { R square } \\
\text { change }\end{array}$ & $\mathrm{F}$ & $\mathrm{p}$ \\
\hline STAI -Trait & .401 & .042 & .000 & .01 & .944 & .502 & .024 & .000 & .00 & .984 \\
\hline BDI-II & .506 & .008 & .035 & 1.08 & .309 & .551 & .012 & .001 & .02 & .882 \\
\hline MPQ-NEM & .423 & .031 & .017 & .50 & .486 & .575 & .008 & .001 & .01 & .906 \\
\hline
\end{tabular}

STAI = Spielberger State Trait Anxiety Inventory; BDI-II = Beck Depression InventoryII; MPQ-NEM = Negative Emotionality factor of the Multidimensional Personality Questionnaire-Brief Form. $\mathrm{r}$ is the Pearson correlation coefficient, and $\mathrm{p}$ its associated (2-tailed) probability. R Square Change was derived after entry (step 2) of each individual psychometric measure showing its prediction of STS BOLD response (fearneutral difference) and Right Amygdala BOLD response (fear-neutral difference) after first accounting for variance in negative affectivity component scores. $F$ and $p$ values are for R Square Change. noted association for fear faces, we conducted a regression analysis in which fear-neutral and happy-neutral difference scores were included together as predictors of NA component scores. Within the model, differential reactivity to fearful faces contributed uniquely to prediction $(\beta=.46, p=.05)$, whereas differential reactivity to happy faces did not $(\beta=.25, p>.27)$. The implication is that the effect for happy faces in the invisible condition (i.e., augmented amygdala reactivity relative to neutral faces for individuals high in NA) was tied in some way to the corresponding effect for fear faces.

\section{Discussion}

Individual differences in brain response to affective face stimuli

The current study was the first to use CFS and functional neuroimaging to study variations in brain reactivity to emotional stimuli in relation to distinct dispositional constructs of NA and fear. Consistent with prior work demonstrating differences in amygdala reactivity for individuals high on traits such as anxiousness and neuroticism (Bishop et al., 2007; Chan et al., 2009; Dickie and Armony, 2008; Etkin et al., 2004; Ewbank et al., 2009; Haas et al., 2007; Stein et al., 2007), we found that individuals high in dispositional NA showed enhanced fear-neutral differentiation in the amygdala as well as in the superior temporal sulcus (STS) but not in the fusiform face area (FFA). Given prior evidence for covariation in STS and amygdala reactivity to invisible fear faces (Jiang and He, 2006) along with previous work indicating that the activation in the amygdala occurs prior to the onset of activity in the STS (Jiang et al., 2009), the response to fearful faces observed in the STS may be modulated by the amygdala. The current findings further extend prior research by demonstrating robust prediction of amygdala reactivity to emotional stimuli for a broad NA dimension that encompasses anxiousness and neuroticism along with other trait constructs such as distress, dysphoria, alienation, and hostility. In addition, consistent with prediction, high NA was associated with enhanced amygdala reactivity to affective faces of other types besides fear (i.e., happy). Contrary to prediction, however, these amygdala reactivity differences for participants high in NA emerged robustly in the invisible processing condition only, and no effects of this type were observed for high versus low fear participants.

While contrary to predictions based on startle research evidence (Vaidyanathan et al., 2009a), the null results for trait fear in the current study are nonetheless consistent with some prior research (Hariri et al., 2002, presented to the other eye 2005) indicating a lack of association between amygdala reactivity to visible fear faces and scores on the TPQHarm Avoidance scale. This prior work is relevant to the current findings because the TPQ Harm Avoidance scale functions as an indicator of trait fear (Kramer et al., 2011) and it served as a source of items for the trait fear measure utilized in the current study (Patrick and Bernat, 2010). The dispositional fear construct indexed by this measure can be conceptualized as related to, but distinct from, anxiety- or distress-proneness (i.e., negative affectivity; Watson and Tellegen, 1985) as indexed by measures such as the STAI.

\section{Dispositional fear and negative affectivity: commonalities and distinctions}

Although correlated, dispositional constructs of NA and fear can nonetheless be distinguished psychologically and neurobiologically. Increased vigilance for possible adverse events and hypersensitivity to novel or ambiguous stimuli are notable features of NA. By contrast, dispositional fear reflects proneness to defensive activation in the presence of immediate threat cues (Patrick and Bernat, 2010; Vaidyanathan et al., 2009a). From this standpoint, heightened amygdala response to fear faces in high NA individuals may reflect processes related to attentional vigilance, wariness, and anticipation of potential threats more so than priming of defensive actions. 
The two constructs can also be distinguished neurobiologically. The central nucleus of the amygdala (CeA) plays a stronger role in phasic fear, whereas the lateral division of the bed nucleus of the stria terminalis (BNST) contributes more to sustained negative affect (Davis, 2006; Davis and Shi, 1999; Walker et al., 2003; Walker and Davis, 2008). In humans, the BNST has also been implicated in the general hypervigilance evident among high trait anxious individuals (Somerville et al., 2010). Notably, the CeA and BNST both rely on input from the basolateral amygdala to become activated-with signaling of one or the other system dependent upon the nature and strength of the input received. From this standpoint, BOLD signal change in the amygdala within differing tasks could reflect processes related to the evaluation of stimulus input (basolateral amygdala) or processes related to the acute mobilization of defensive response (central amygdala)-or perhaps both. Although follow-up research is needed to support strong conclusions, the current results appear consistent with the idea that enhanced amygdala response to invisible fear faces in individuals with high NA reflects heightened activity of the basolateral input subsystem more so than the central output system.

In line with this, pleasurable and aversive pictures are known to activate the sublenticular extended amygdala (amygdaloid nuclei, sublenticular nuclei, nucleus accumbens; Liberzon et al., 2003), whereas facial expression-evoked signal changes have been localized bilaterally to the superficial amygdala (anterior amygdala area, ventral and posterior cortical nuclei; Goossens et al., 2009). Further, in contrast with more intense aversive cues such as directly threatening scenes or visual displays signaling shock delivery, fearful faces do not prompt reliable startle reflex potentiation when presented as foreground stimuli (Dunning et al., 2010; Hess et al., 2007; Springer et al., 2007). The implication is that amygdala reactivity to fear faces may reflect activation of the basolateral amygdala and structures to which it projects (e.g., BNST) rather than activation of the CeA that characterizes cue-elicited fear.

Insofar as differing subdivisions of the defensive motivational system are theorized to play differing roles in trait fear and negative affectivity, they have been posited to account for contrasting experimental effects observed for these two dispositional constructs. Consistent with Davis's idea of startle potentiation during aversive cuing as indicative of phasic fear mediated by the CeA, levels of trait fear show covariation with levels of startle potentiation during aversive cuing whereas measures indicative of trait anxiousness and distress covary less reliably with this index of phasic defensive activation (Vaidyanathan et al., 2009b). A similar dissociation in effects is evident for phobic disorders (e.g., specific and social phobia) in comparison with distress disorders (e.g., depression, generalized anxiety disorder). Specifically, heightened levels of startle potentiation during fear cue exposure are reliably observed in phobic disorders whereas distress disorders appear to be associated with increased contextual potentiation of startle, defined as persisting augmentation of startle (relative to baseline) under conditions of uncertainty or unpredictable stress (Vaidyanathan et al., 2009b). The latter finding in particular is consistent with Davis' notion of differential neural substrates for phasic fear versus tonic anxiety.

Possible mechanisms for enhanced brain reactivity to invisible fear faces in high NA individuals

The selectivity of associations for fear face reactivity with measures of dispositional negative affect, as opposed to dispositional fear, raises questions about the nature of the underlying psychological process(es) reflected by STS/amygdala reactivity to fear faces, and what brain mechanism might account for isolation of individual difference effects to the invisible processing condition. One possibility, highlighted in preceding sections, is that differing subdivisions of the amygdala may account for fear face effects as compared to aversive startle potentiation effects. Whereas potentiation of the defensive startle reflex is mediated by the output subdivision of the amygdala (i.e., CeA), it can be hypothesized that amygdala reactivity in fMRI face-processing paradigms may instead reflect activity of the input (basolateral) subsystem-and potentially of the BNST, the affiliated system that mediates more sustained negative emotional reactions, corresponding to anxiety. From this standpoint, amygdala reactivity to fear faces may not reflect stimulus-specific fear reactivity, which would be expected (based on evidence from startle research studies) to covary more with the construct of trait fear than with negative affectivity, but instead more diffuse activation of cognitive-affective representational networks in the brain (Lang, 1979).

Notably, high NA participants in the current study, besides showing enhanced amygdala reactivity to invisible fearful versus neutral faces, also showed evidence of enhanced amygdala reactivity to invisible happy as compared to neutral faces. This finding extends prior evidence indicating sensitivity of the amygdala to positively valent stimuli as well as negatively valent stimuli (Hamann et al., 1999; Pessoa et al., 2002; van der Gaag et al., 2007; Whalen et al., 1998; Yang et al., 2002) and suggests that high dispositional negative affectivity entails not just heightened sensitivity and receptivity to fear stimuli, but heightened sensitivity to cues of varying types in the environment that carry motivational significance.

The observed pattern of results and affiliated interpretations in turn raise questions about pathways by which the amygdala becomes active in so-called "invisible" affect-processing paradigms. Whereas some investigators (e.g., Ohman and Soares, 1994) have theorized that direct neural connections between the sensory thalamus or primary visual cortex and the amygdala (i.e., "low-road" connections) mediate affective processing under conditions of unawareness, others have argued for a 'multiple roads' perspective, in which the amygdala coordinates the function of cortical networks during evaluation of the motivational significance of affective stimuli (Pessoa and Adolphs, 2010; Tsuchiya et al., 2009).

\section{Limitations and future directions}

Two limitations of the current study should be acknowledged. First, the sample size, although respectable for a neuroimaging study, was quite modest for a non-MRI individual differences study. This limitation was accentuated in some analyses by the loss of data for particular ROIs (the amygdala, most notably) for some participants. Second, owing to the modest sample size and need to optimize power, results were reported for specific a priori ROIs. In future studies with larger samples, it will be useful to conduct whole brain random effect analyses in order to evaluate contributions of other structures to the processing of invisible affective stimuli.

Notwithstanding these limitations, the current study introduces an innovative new methodology for investigating mechanisms of affective processing in psychopathology and related individual difference constructs. Although the current study focused on nonclinical participants, the individual difference constructs of trait fear and NA have direct counterparts in the psychopathology literature-namely, fear disorders (encompassing social phobia, simple phobia, agoraphobia, and panic disorder) and distress disorders (encompassing unipolar depression, dysthymia, generalized anxiety, and post-traumatic stress disorder; Krueger, 1999; Watson, 2005). While overlapping, these two groups of disorders are nonetheless distinguishable in that: (1) dispositional NA accounts for substantially more variance in the distress disorders than the fear disorders, and (2) the fear disorders are characterized by prominent hyperarousal-either in relation to specific stimulus cues as seen in simple and social phobia, or internal physiologic cues as seen in panic disorder (Watson, 2005). Further research utilizing the CFS procedure with patients exhibiting fear and distress disorders will be valuable for clarifying the role of differing brain structures and circuits in disorders of each type. The CFS paradigm is recommended as a tool for investigating roles of subcortical-limbic relative to higher cortical 
systems in processing of affective cues in various contexts. Research using this paradigm is likely to be valuable not only for clarifying neuroanatomical networks involved in basic affective processing, but also for elucidating affective processing and regulatory deficits evident in psychiatric disorders.

Supplementary materials related to this article can be found online at doi:10.1016/j.neuroimage.2011.07.015.

\section{Acknowledgments}

This research was supported by the National Institute of Mental Health (NIMH) (MH089727 to CJP; Center support from MH072850 (CJP); HD007151 to NV; postdoctoral support for NV from MH17140); and the National Basic Research Program of China (No. 2011CB711000) and the National Natural Science Foundation of China (No. 31070903) to YJ. The 3T scanner at the University of Minnesota is supported by BTRRP41 008079 and NCCP30 NS057091.

We wish to thank Siri A. Scott and Andrew Harrigan for their assistance with recruitment of participants and data acquisition, and Drs. Bruce N. Cuthbert and Ian A. Cook for helpful scholarly input.

\section{References}

Altshuler, L., Bookheimer, S., Proenza, M.A., Townsend, J., Sabb, F., Firestine, A., Bartzokis, G., Mintz, J., Mazziotta, J., Cohen, M.S., 2005. Increased amygdala activation during mania: a functional magnetic resonance imaging study. Am. J. Psychiatry 162, 1211-1213.

Amting, J.M., Greening, S.G., Mitchell, D.G., 2010. Multiple mechanisms of consciousness: the neural correlates of emotional awareness. J. Neurosci. 30, 10039-10047.

Anand, A., Shekhar, A., 2003. Brain imaging studies in mood and anxiety disorders: special emphasis on the amygdala. Ann. N. Y. Acad. Sci. 985, 370-388.

Armony, J.L., Corbo, V., Clement, M.H., Brunet, A., 2005. Amygdala response in patients with acute PTSD to masked and unmasked emotional facial expressions. Am. J. Psychiatry 162, 1961-1963.

Arrindell, W.A., Emmelkamp, P.M.G., Jan, v.d.E., 1984. Phobic dimensions: I. Reliability and generalizability across samples, gender and nations : the fear survey schedule (FSS-III) and the fear questionnaire (FQ). Adv. Behav. Res. Ther. 6, 207-253.

Barlow, D.H., 2002. Anxiety and its disorders : the nature and treatment of anxiety and panic, 2nd ed. Guilford Press, New York.

Beck, A.T., Steer, R.A., Brown, G.K., 1996. Manual for the Beck Depression Inventory-II. Psychological Corporation, San Antonio, TX

Bishop, S.J., Jenkins, R., Lawrence, A.D., 2007. Neural processing of fearful faces: effects of anxiety are gated by perceptual capacity limitations. Cereb. Cortex 17, 1595-1603.

Blake, R., Logothetis, N.K., 2002. Visual competition. Nat. Rev. Neurosci. 3, 13-21.

Buracas, G.T., Boynton, G.M., 2002. Efficient design of event-related fMRI experiments using M-sequences. Neuroimage 16, 801-813.

Buss, A.H., Plomin, R., 1984. Temperament : early developing personality traits. L. Erlbaum Associates, Hillsdale, N.J.

Chan, S.W., Norbury, R., Goodwin, G.M., Harmer, C.J., 2009. Risk for depression and neural responses to fearful facial expressions of emotion. Br. J. Psychiatry 194, 139-145.

Clark, L.A., Watson, D., 1991. Tripartite model of anxiety and depression: psychometric evidence and taxonomic implications. J. Abnorm. Psychol. 100, 316-336.

Cloninger, C.R., 1987. A systematic method for clinical description and classification of personality variants. A proposal. Arch. Gen. Psychiatry 44, 573-588.

Dannlowski, U., Ohrmann, P., Bauer, J., Kugel, H., Arolt, V., Heindel, W., Kersting, A., Baune, B.T., Suslow, T., 2007. Amygdala reactivity to masked negative faces is associated with automatic judgmental bias in major depression: a 3T fMRI study. J. Psychiatry Neurosci. 32, 423-429.

Dannlowski, U., Ohrmann, P., Bauer, J., Deckert, J., Hohoff, C., Kugel, H., Arolt, V., Heindel, W., Kersting, A., Baune, B.T., Suslow, T., 2008. 5-HTTLPR biases amygdala activity in response to masked facial expressions in major depression. Neuropsychopharmacology 33, 418-424.

Davis, M., 1986. Pharmacological and anatomical analysis of fear conditioning using the fear-potentiated startle paradigm. Behav. Neurosci. 100, 814-824.

Davis, M., 2006. Neural systems involved in fear and anxiety measured with fearpotentiated startle. Am. Psychol. 61, 741-756.

Davis, M., Shi, C., 1999. The extended amygdala: are the central nucleus of the amygdala and the bed nucleus of the stria terminalis differentially involved in fear versus anxiety? Ann. N. Y. Acad. Sci. 877, 281-291.

Dickie, E.W., Armony, J.L., 2008. Amygdala responses to unattended fearful faces: interaction between sex and trait anxiety. Psychiatry Res. 162, 51-57.

Dunning, J.P., Auriemmo, A., Castille, C., Hajcak, G., 2010. In the face of anger: startle modulation to graded facial expressions. Psychophysiology 47, 874-878.

Edwards, M.S., Burt, J.S., Lipp, O.V., 2010a. Selective attention for masked and unmasked emotionally toned stimuli: effects of trait anxiety, state anxiety, and test order. $\mathrm{Br}$. J. Psychol. 101, 325-343.
Edwards, M.S., Burt, J.S., Lipp, O.V., 2010b. Selective attention for masked and unmasked threatening words in anxiety: effects of trait anxiety, state anxiety and awareness. Behav. Res. Ther. 48, 210-218.

Etkin, A., Klemenhagen, K.C., Dudman, J.T., Rogan, M.T., Hen, R., Kandel, E.R., Hirsch, J. 2004. Individual differences in trait anxiety predict the response of the basolateral amygdala to unconsciously processed fearful faces. Neuron 44, 1043-1055.

Ewbank, M.P., Lawrence, A.D., Passamonti, L., Keane, J., Peers, P.V., Calder, A.J., 2009 Anxiety predicts a differential neural response to attended and unattended facial signals of anger and fear. Neuroimage 44, 1144-1151.

Fang, F., He, S., 2005. Cortical responses to invisible objects in the human dorsal and ventral pathways. Nat. Neurosci. 8, 1380-1385.

Felmingham, K., Williams, L.M., Kemp, A.H., Liddell, B., Falconer, E., Peduto, A., Bryant, R., 2010. Neural responses to masked fear faces: sex differences and trauma exposure in posttraumatic stress disorder. J. Abnorm. Psychol. 119, 241-247.

First, M.B., Spitzer, R.L., Gibbon, M., Williams, J.B.W., 1997. Structured Clinical Interview for DSM-IV Personality Disorders (SCID-II). American Psychiatric Press, Inc. Washington, DC.

First, M.B., Spitzer, R.L., Gibbon, M., Williams, J.B.W., 2007. Structured Clinical Interview for DSM-IV-TR Axis I Disorders, Non-patient Edition (SCID-I/NP,1/2007 revision). Biometrics Research, New York State Psychiatric Institute, New York.

Fitzgerald, D.A., Angstadt, M., Jelsone, L.M., Nathan, P.J., Phan, K.L., 2006. Beyond threat: amygdala reactivity across multiple expressions of facial affect. Neuroimage 30, 1441-1448.

Ghashghaei, H.T., Hilgetag, C.C., Barbas, H., 2007. Sequence of information processing for emotions based on the anatomic dialogue between prefrontal cortex and amygdala. Neuroimage 34, 905-923.

Globisch, J., Hamm, A.O., Esteves, F., Ohman, A., 1999. Fear appears fast: temporal course of startle reflex potentiation in animal fearful subjects. Psychophysiology 36 , 66-75.

Goossens, L., Kukolja, J., Onur, O.A., Fink, G.R., Maier, W., Griez, E., Schruers, K., Hurlemann, R., 2009. Selective processing of social stimuli in the superficial amygdala. Hum. Brain Mapp. 30, 3332-3338.

Haas, B.W., Omura, K., Constable, R.T., Canli, T., 2007. Emotional conflict and neuroticism: personality-dependent activation in the amygdala and subgenual anterior cingulate. Behav. Neurosci. 121, 249-256.

Hamann, S.B., Ely, T.D., Grafton, S.T., Kilts, C.D., 1999. Amygdala activity related to enhanced memory for pleasant and aversive stimuli. Nat. Neurosci. 2, 289-293.

Hammar, A., Sorensen, L., Ardal, G., Oedegaard, K.J., Kroken, R., Roness, A., Lund, A. 2009. Enduring cognitive dysfunction in unipolar major depression: a test-retest study using the Stroop paradigm. Scand. J. Psychol. 51, 304-308.

Hariri, A.R., Mattay, V.S., Tessitore, A., Kolachana, B., Fera, F., Goldman, D., Egan, M.F. Weinberger, D.R., 2002. Serotonin transporter genetic variation and the response of the human amygdala. Science 297, 400-403.

Hariri, A.R., Drabant, E.M., Munoz, K.E., Kolachana, B.S., Mattay, V.S., Egan, M.F., Weinberger, D.R., 2005. A susceptibility gene for affective disorders and the response of the human amygdala. Arch. Gen. Psychiatry 62, 146-152.

Haxby, J.V., Hoffman, E.A., Gobbini, M.I., 2000. The distributed human neural system for face perception. Trends Cogn. Sci. 4, 223-233.

Hess, U., Sabourin, G., Kleck, R.E., 2007. Postauricular and eyeblink startle responses to facial expressions. Psychophysiology 44, 431-435.

Hicks, B.M., Patrick, C.J., 2006. Psychopathy and negative emotionality: analyses of suppressor effects reveal distinct relations with emotional distress, fearfulness, and anger-hostility. J. Abnorm. Psychol. 115, 276-287.

Hoistad, M., Barbas, H., 2008. Sequence of information processing for emotions through pathways linking temporal and insular cortices with the amygdala. Neuroimage 40 , 1016-1033.

Insel, T., Cuthbert, B., Garvey, M., Heinssen, R., Pine, D.S., Quinn, K., Sanislow, C., Wang P., 2010. Research domain criteria (RDoC): toward a new classification framework for research on mental disorders. Am. J. Psychiatry 167, 748-751.

Jansson, B., Najstrom, M., 2009. Is preattentive bias predictive of autonomic reactivity in response to a stressor? J. Anxiety Disord. 23, 374-380.

Jiang, Y., He, S., 2006. Cortical responses to invisible faces: dissociating subsystems for facial-information processing. Curr. Biol. 16, 2023-2029.

Jiang, Y., Shannon, R.W., Vizueta, N., Bernat, E.M., Patrick, C.J., He, S., 2009. Dynamics of processing invisible faces in the brain: automatic neural encoding of facial expression information. Neuroimage $44,1171-1177$

Johnstone, T., Somerville, L.H., Alexander, A.L., Oakes, T.R., Davidson, R.J., Kalin, N.H. Whalen, P.J., 2005. Stability of amygdala BOLD response to fearful faces over multiple scan sessions. Neuroimage 25, 1112-1123.

Kim, C.Y., Blake, R., 2005. Psychophysical magic: rendering the visible 'invisible'. Trends Cogn. Sci. 9, 381-388.

Kramer, M., Patrick, C.J., Krueger, R.F., Gasperi, M., 2011. Delineating Physiologic Defensive Reactivity in the Domain of Self Report: Phenotypic and Etiologic Structure of Fear and Fearlessness Measures. Manuscript submitted for publication.

Krueger, R.F., 1999. The structure of common mental disorders. Arch. Gen. Psychiatry 56, 921-926.

Lang, P.J., 1979. Presidential address, 1978. A bio-informational theory of emotional imagery. Psychophysiology 16, 495-512.

Lang, P.J., 1980. Behavioral treatment and bio-behavioral assessment: computer applications. In: Sidowski, J., Johnson, J., Williams, T. (Eds.), Technology in Menta Health Care Delivery Systems. Ablex Pub. Corp, Norwood, NJ, pp. 119-137.

Lang, P.J., Bradley, M.M., Cuthbert, B.N., 1990. Emotion, attention, and the startle reflex. Psychol. Rev. 97, 377-395.

Liberzon, I., Phan, K.L., Decker, L.R., Taylor, S.F., 2003. Extended amygdala and emotional salience: a PET activation study of positive and negative affect. Neuropsychopharmacology 28, 726-733. 
Lilienfeld, S.O., Andrews, B.P., 1996. Development and preliminary validation of a selfreport measure of psychopathic personality traits in noncriminal populations. J. Pers. Assess. 66, 488-524.

McClure, E.B., Monk, C.S., Nelson, E.E., Parrish, J.M., Adler, A., Blair, R.J., Fromm, S Charney, D.S., Leibenluft, E., Ernst, M., Pine, D.S., 2007. Abnormal attention modulation of fear circuit function in pediatric generalized anxiety disorder. Arch. Gen. Psychiatry 64, 97-106.

Monk, C.S., Telzer, E.H., Mogg, K., Bradley, B.P., Mai, X., Louro, H.M., Chen, G., McClureTone, E.B., Ernst, M., Pine, D.S., 2008. Amygdala and ventrolateral prefrontal cortex activation to masked angry faces in children and adolescents with generalized anxiety disorder. Arch. Gen. Psychiatry 65, 568-576.

Ohman, A., Soares, J.J., 1994. "Unconscious anxiety": phobic responses to masked stimuli. J. Abnorm. Psychol. 103, 231-240.

Pasley, B.N., Mayes, L.C., Schultz, R.T., 2004. Subcortical discrimination of unperceived objects during binocular rivalry. Neuron 42, 163-172.

Patrick, C.J., Bernat, E.M., 2010. Neuroscientific foundations of psychopathology. In: Millon, T., Krueger, R.F., Simonsen, E. (Eds.), Contemporary directions in psychopathology: Toward the DSM-V. Guilford Press, New York, pp. 419-452.

Patrick, C.J., Curtin, J.J., Tellegen, A., 2002. Development and validation of a brief form of the Multidimensional Personality Questionnaire. Psychol. Assess. 14, 150-163.

Pessoa, L., Adolphs, R., 2010. Emotion processing and the amygdala: from a 'low road' to 'many roads' of evaluating biological significance. Nat. Rev. Neurosci. 11, 773-783.

Pessoa, L., McKenna, M., Gutierrez, E., Ungerleider, L.G., 2002. Neural processing of emotional faces requires attention. Proc. Natl. Acad. Sci. U.S.A. 99, 11458-11463.

Phan, K.L., Fitzgerald, D.A., Nathan, P.J., Tancer, M.E., 2006. Association between amygdala hyperactivity to harsh faces and severity of social anxiety in generalized social phobia. Biol. Psychiatry 59, 424-429.

Rauch, S.L., Whalen, P.J., Shin, L.M., McInerney, S.C., Macklin, M.L., Lasko, N.B., Orr, S.P., Pitman, R.K., 2000. Exaggerated amygdala response to masked facial stimuli in posttraumatic stress disorder: a functional MRI study. Biol. Psychiatry 47, 769-776.

Rauch, S.L., Shin, L.M., Wright, C.I., 2003. Neuroimaging studies of amygdala function in anxiety disorders. Ann. N. Y. Acad. Sci. 985, 389-410.

Sanislow, C.A., Pine, D.S., Quinn, K.J., Kozak, M.J., Garvey, M.A., Heinssen, R.K., Wang, P.S Cuthbert, B.N., 2010. Developing constructs for psychopathology research: research domain criteria. J. Abnorm. Psychol. 119, 631-639.

Somerville, L.H., Whalen, P.J., Kelley, W.M., 2010. Human bed nucleus of the stria terminalis indexes hypervigilant threat monitoring. Biol. Psychiatry 68, 416-424.

Speilberger, C.D., 1983. Manual for the State-Trait Anxiety Inventory (Form Y-1) Consulting Psychologists Press, Palo Alto, CA.

Springer, U.S., Rosas, A., McGetrick, J., Bowers, D., 2007. Differences in startle reactivity during the perception of angry and fearful faces. Emotion 7, 516-525.

Stein, M.B., Simmons, A.N., Feinstein, J.S., Paulus, M.P., 2007. Increased amygdala and insula activation during emotion processing in anxiety-prone subjects. Am. Psychiatry 164, 318-327.

Sullivan, H.S., 1949. The theory of anxiety and the nature of psychotherapy. Psychiatry $12,3-12$

Suslow, T., Konrad, C., Kugel, H., Rumstadt, D., Zwitserlood, P., Schoning, S., Ohrmann, P., Bauer, J., Pyka, M., Kersting, A., Arolt, V., Heindel, W., Dannlowski, U., 2010. Automatic mood-congruent amygdala responses to masked facial expressions in major depression. Biol. Psychiatry 67, 155-160.
Talairach, J., Tournoux, P., 1988. Co-planar stereotaxic atlas of the human brain: 3Dimensional Proportional System: An Approach to Cerebral Imaging. Thieme Medical Publishers, Inc., New York.

Tellegen, A., 1985. Structures of Mood and Personality and Their Relevance to Assessing Anxiety, With an Emphasis on Self-Report. In: Tuma, A.H., Maser, J.D. (Eds.), Anxiety and the anxiety disorders. Lawrence Erlbaum Associates, Hillsdale, NJ, pp. 681-715.

Tellegen, A., 2003. Multidimensional Personality Questionnaire-276 (MPQ-276), test booklet. University of Minnesota Press, Minneapolis, MN.

Thomas, K.M., Drevets, W.C., Dahl, R.E., Ryan, N.D., Birmaher, B., Eccard, C.H., Axelson, D., Whalen, P.J., Casey, B.J., 2001. Amygdala response to fearful faces in anxious and depressed children. Arch. Gen. Psychiatry 58, 1057-1063.

Tottenham, N., Tanaka, J.W., Leon, A.C., McCarry, T., Nurse, M., Hare, T.A., Marcus, D.J., Westerlund, A., Casey, B.J., Nelson, C., 2009. The NimStim set of facial expressions: judgments from untrained research participants. Psychiatry Res. 168, 242-249.

Tsuchiya, N., Koch, C., 2005. Continuous flash suppression reduces negative afterimages. Nat. Neurosci. 8, 1096-1101.

Tsuchiya, N., Moradi, F., Felsen, C., Yamazaki, M., Adolphs, R., 2009. Intact rapid detection of fearful faces in the absence of the amygdala. Nat. Neurosci. 12,1224-1225.

Vaidyanathan, U., Patrick, C.J., Bernat, E.M., 2009a. Startle reflex potentiation during aversive picture viewing as an indicator of trait fear. Psychophysiology 46, 75-85.

Vaidyanathan, U., Patrick, C. Cuthbert, B.N. 2009b. Linking dimensional models of internalizing psychopathology to neurobiological systems: affect-modulated startle as an indicator of fear and distress disorders and affiliated traits. Psychol. Bull. 135, 909-942.

van der Gaag, C., Minderaa, R.B., Keysers, C., 2007. The BOLD signal in the amygdala does not differentiate between dynamic facial expressions. Soc. Cogn. Affect. Neurosci. 2, 93-103.

Victor, T.A., Furey, M.L., Fromm, S.J., Ohman, A., Drevets, W.C., 2010. Relationship between amygdala responses to masked faces and mood state and treatment in major depressive disorder. Arch. Gen. Psychiatry 67, 1128-1138.

Walker, D.L., Davis, M., 2008. Role of the extended amygdala in short-duration versus sustained fear: a tribute to Dr. Lennart Heimer. Brain Struct. Funct. 213, 29-42.

Walker, D.L., Toufexis, D.J., Davis, M., 2003. Role of the bed nucleus of the stria terminalis versus the amygdala in fear, stress, and anxiety. Eur. J. Pharmacol. 463, 199-216.

Watson, D., 2005. Rethinking the mood and anxiety disorders: a quantitative hierarchical model for DSM-V. J. Abnorm. Psychol. 114, 522-536.

Watson, D., Tellegen, A., 1985. Toward a consensual structure of mood. Psychol. Bull. 98, 219-235.

Whalen, P.J., Rauch, S.L., Etcoff, N.L., McInerney, S.C., Lee, M.B., Jenike, M.A., 1998. Masked presentations of emotional facial expressions modulate amygdala activity without explicit knowledge. J. Neurosci. 18, 411-418.

Williams, M.A., Morris, A.P., McGlone, F., Abbott, D.F., Mattingley, J.B., 2004. Amygdala responses to fearful and happy facial expressions under conditions of binocular suppression. J. Neurosci. 24, 2898-2904.

Yang, T.T., Menon, V., Eliez, S., Blasey, C., White, C.D., Reid, A.J., Gotlib, I.H., Reiss, A.L., 2002. Amygdalar activation associated with positive and negative facial expressions. Neuroreport 13, 1737-1741

Zuckerman, M., 1979. Sensation seeking: beyond the optimal level of arousal. Lawrence Erlbaum Assoc, Hillsdale, NJ. 